\title{
EL MODELO DEL OPERÓN LAC 50 AÑOS DESPUÉS. ¿QUÉ IMPLICACIONES TIENE EN LA ENSEÑANZA DE LA BIOLOGÍA HOY?
}

\section{THE LAC OPERON MODEL 50 YEARS LATER. WHAT IMPLICATIONS DOES IT HAVE IN BIOLOGY'S TEACHING TODAY?}

\section{Por: Julio Alejandro Castro Moreno²}

\begin{tabular}{|l|}
\hline Recibido: $26-09-2011$ \\
\hline Aceptado: $22-11-2011$ \\
\hline
\end{tabular}

\section{Resumen}

El texto es una invitación a tomarse en serio la conmemoración del medio siglo de "vida" del modelo del operón Lac. En particular, se hace una reflexión acerca de qué podemos aprender de ese modelo para la didáctica de la biología en la actualidad. A este respecto, se destaca la importancia de los procesos de modelización en las estrategias de enseñanza de la biología.

Palabras clave. Modelo del operón Lac, historia de la biología, implicaciones didácticas, regulación genética, modelización.

\section{Abstract}

This paper is an invitation to take the celebration of the Lac operon model"s "life" the half-century seriously. In special, a reflection on what we can learn from that model for biology didactics today is carried out. In this regard, the importance of modeling processes in biology teaching strategies is stressed.

Keywords: Operon model, biology history, didactic implications, genetic regulation, modeling.

Una vez publicado, el modelo del operón fracasó estrepitosamente. Quizás era excesivo, porque lo pusimos en todas las salsas, incluso en dominios con los que nada tenía que ver. Se propusieron otros modelos para explicar la regulación de los genes en las bacterias mediante mecanismos diversos, algunos radicalmente distintos del nuestro. Los bioquímicos los desmintieron rápidamente (...) El estudio molecular de la regulación se hizo entonces posible. Los elementos hallados constituían ciertamente una unidad de regulación, cuyas propiedades se correspondían, con alguna que otra modificación menor, con las que había previsto nuestro modelo.

François Jacob, "El ratón, la mosca y el hombre", 1998.

Recientemente tuve la oportunidad de asistir a una conferencia titulada "Fifty years after the operon model: the French school of molecular biology,3, que fue impartida por el historiador francés de la ciencia Michel Morange ${ }^{4}$. Me llamó mucho la atención la gran concurrencia de público, en especial jóvenes que se están formando como biólogos, y me causó mayor asombro el interés que aún despierta el tema del modelo del operón, particularmente en el ámbito de la historia de la biología. Ciertamente, Morange no dijo una palabra acerca de cómo las reflexiones planteadas en su

${ }^{1}$ En los diferentes textos consultados y referenciados en este ensayo no he hallado una forma estándar de referirse a este modelo, por lo tanto opto por utilizar la nominación empleada por Jacob y Monod (1961), aunque cabe aclarar que ellos no aluden al "modelo del operón Lac" en ese artículo, sino que denominan así a una región del genoma de E. coli: "lactose region" o "Lac region".

2 Profesor del Departamento de Biología, Universidad Pedagógica Nacional, Bogotá. Doctorando en Filosofía de la Ciencia, Universidad Nacional Autónoma de México. Dirección de contacto: icastro@pedagogica.edu.co

3 "Cincuenta años después del modelo del operón: la escuela francesa de biología molecular". Esta conferencia tuvo lugar en el auditorio Carlos Graef, sala Amoxcalli, de la Facultad de Ciencias de la Universidad Nacional Autónoma de México, el 7 de septiembre de 2011.

${ }_{4}^{4}$ École Normale Supérieure, Paris. 
conferencia podrían motivar cuestionamientos acerca de la enseñanza de la biología hoy. No tenía que hacerlo, no era su tema, pero a lo largo de su charla me surgieron algunas preguntas que me motivaron a escribir estas cortas líneas. No está de más decir que el título de este escrito es una adaptación del título de la conferencia citada.

He estudiado con cierto detalle el tema de cómo se instituyó el modelo del operón $L a c^{5}$, pero estas indagaciones las he hecho en el marco de entender las implicaciones didácticas y filosóficas de este saber en particular. No entraré en detalles sobre los aspectos "netamente" biológicos de este modelo", porque ello nos desviaría de las ideas que quiero plantear y, por otro lado, porque esto ya lo he hecho, en especial en Castro (2006). Así pues, permítaseme esbozar un marco histórico, para luego cerrar con las implicaciones didácticas de un quincuagésimo aniversario que ha pasado casi desapercibido, no sólo en la comunidad de biólogos, sino de profesores de biología, y de todos aquéllos que estén interesados en la historia y la filosofía de esta ciencia.

Dicho esto, una primera pregunta salta a la vista. ¿Por qué este año se celebran las "bodas de oro" de este modelo científico? No se puede decir con exactitud cuándo un saber científico ve la luz por primera vez. Piénsese, por ejemplo, en el "Origen de las especies" de Darwin: fue publicado en $1859^{7}$, pero le llevó toda una vida a este naturalista escribir y reescribir (en un total de 6 ediciones) las ideas que quería expresar. Darwin tardó más o menos veinte años para que finalmente pudiera plasmar sus planteamientos en la primera edición de su magnífico texto. Con el modelo del operón pasa algo similar (de hecho creo que esto ocurre en general en la ciencia), pues Jacob empezó a trabajar a inicios de la década de 1950 en el Instituto Pasteur de París, primero con Lwoff sobre la lisogenia y luego con Monod sobre el tema de la "adaptación enzimática".

Años después surgió la idea de "operón", cuya primera definición la encontramos, quizá, en este párrafo:

\begin{abstract}
L'hypothèse de l'opérateur implique qu'entre le gène classique, unité indépendante de fonction biochimique, et le chromosome entier, il existe une organisation génétique intermédiaire. Celle-ci comprendrait des unités d'expression coordonnée (opérons) constituées par un opérateur et le groupe de gènes de structures coordonnées par lui. Chaque opéron serait, par l'intermédiaire de l'opérateur, soumis á l'action d'un répresseur dont la synthèse serait régie par un gène régulateur (non nécessairement lié au groupe) (Jacob, Perrin, Sánchez et Monod, 1960, citados por Navarro, 2002).
\end{abstract}

No obstante, el modelo del operón Lac fue publicado (en todas las salsas, como lo expresa Jacob en el epigrafe), por primera vez en 1961, en un artículo titulado "Genetic regulatory mechanisms in the synthesis of proteins" en el naciente Journal of Molecular Biology. Así pues, ese artículo fundacional puede ser considerado como el acta de nacimiento del modelo en cuestión ${ }^{9}$.

\footnotetext{
${ }^{5}$ Véanse Castro (2005, 2006, 2007, 2008 y 2010).

${ }^{6}$ Tampoco aludiré a otros procesos de regulación génica, como, por ejemplo, los que están implicados en los organismos eucariotas, en donde el asunto se torna muy complejo.

${ }^{7}$ Dicho sea de paso, las celebraciones que en 2009 se llevaron a cabo en todo el mundo con respecto a los 150 años de la publicación del Origen, y con relación al bicentenario del nacimiento de Darwin, difícilmente hubiesen pasado desapercibidas por cualquiera que haga parte de las comunidades académicas interesadas en diferentes aspectos de la biología. Claro, el modelo del operón no revolucionó el mundo, pero sí creo que introdujo varias novedades para entender cómo se regula la información genética en bacterias, lo cual abrió el camino para muchas investigaciones en otro tipo de organismos. En ese sentido, me parece que este aniversario merecería un tributo mayor.

8 "La hipótesis del operador implica que entre el gen clásico, como unidad independiente de función bioquímica, y el cromosoma en su totalidad, existe una organización genética intermediaria. Ella está conformada por unidades de expresión coordinada (operones), los que a su vez están constituidos por un operador y el grupo de genes estructurales coordinados por éste. Cada operón estaría, por intermedio del operador, sometido a la acción de un represor cuya síntesis estaría controlada por un gen regulador (no necesariamente unido al grupo de genes estructurales)" (La traducción es mía).

${ }^{9}$ En Castro (2006) extraigo algunas ideas claves del artículo mencionado y hago una reconstrucción histórica de cómo se propuso y cómo se publicó el modelo del operón.
} 
Desde entonces ha pasado medio siglo, y aún ese modelo es un paradigma (en el sentido literal de ejemplar) para la investigación sobre la regulación genética en diferentes organismos. Cabe recordar que Monod afirmó, a inicios de la década de 1960, que lo que era cierto para el colibacilo ( $E$. coli ${ }^{10}$ ), lo era para el elefante, o sea que, para este autor, existía un único mecanismo de regulación genética en el mundo viviente. Pero también vale la pena señalar que pronto se evidenció que éste no era el caso, entre otras cosas por la "avalancha" de indagaciones que se llevaron a cabo en pocos años sobre mecanismos de regulación en otros procesos metabólicos y en otro tipo de organismos. Sin embargo, hay que reconocer que las investigaciones pioneras de Jacob y Monod han abierto un mundo de posibilidades sobre el tema ${ }^{11}$.

Así las cosas, es preciso resaltar que el trabajo de Jacob, Monod y Lwoff (y de tantos otros), ha sido uno de los pilares de la biología molecular. En particular, se reconoce que este grupo instauró dicha disciplina en el contexto francés que, desde Comte, había sido reacio a aceptar la existencia de entidades abstractas, como los genes que se propusieron a inicios del siglo XX en el contexto de lo que se ha llamado como la genética mendeliana (Gayon y Burian, 2004). Situemos históricamente, aunque de manera muy breve, el lugar de la escuela francesa en la instauración de la biología molecular.

Según Thuillier (1985, pp.19-38), el nacimiento y desarrollo de la biología molecular ha pasado por tres grandes periodos que se resumen a continuación:

- El primero de ellos se denomina romántico, por pretender hallar en lo vivo unas nuevas leyes, ausentes en el mundo de la física. Dicho periodo comienza hacia 1935, con las primeras reflexiones de Max Delbrück sobre las nuevas tareas de la genética. En suma, esta época se caracteriza por una 'migración' de físicos hacia problemas de la biología.

- El segundo periodo ha sido llamado dogmático, y va desde 1953 a 1963. Se le denomina así porque es en este lapso en el que se establece el "dogma central" de la biología. Además, este periodo se caracteriza por la formulación de 1) el modelo de la doble hélice por Watson y Crick; 2) los trabajos sobre el $\mathrm{ARN}_{(\mathrm{m})}$ y el modelo del operón de Jacob y Monod; y 3) los trabajos sobre las bacterias lisogénicas de Lwoff $^{12}$.

- El último periodo se ha denominado académico, y corresponde a la estabilización del cuadro de investigación, que se ha centrado en la explicación del desarrollo embrionario desde el punto de vista molecular.

Dado el tema que estamos tratando, no voy a referirme más a los periodos primero y tercero, y del segundo solamente haré referencia a algunos aportes de los tres biólogos moleculares franceses aludidos en lo que respecta al desarrollo de la biología molecular y, en general, a la comprensión de lo vivo desde esa perspectiva.

Así pues, vale la pena señalar que François Jacob, Jacques Monod y André Lwoff recibieron el premio Nobel de Medicina y Fisiología en 1965 por sus investigaciones sobre "la regulación genética de la síntesis de enzimas y virus" (Ondarza, 1994, p. 78). Por un lado, los trabajos de Jacob y Monod, estuvieron centrados en la comprensión

\footnotetext{
${ }^{10}$ El modelo del operón Lac da cuenta del metabolismo de la lactosa en este organismo.

${ }^{11}$ En García (2009) se abordan diferentes historias del operón y se da cuenta de diversos mecanismos de regulación genética en otros organismos distintos a E. coli, como el erizo de mar Strongylocentrotus purpuratus. Por lo tanto, en la investigación de García se puede ver una contrastación entre procesos regulatorios en bacterias y en animales. Además, en dicho trabajo se exponen aspectos más actuales de la regulación génica, y se hace un estudio a profundidad del trabajo de Jacob y Monod.

${ }^{12}$ En Castro (2007), uso el modelo de la "historia social de las ciencias" de Bruno Latour, para mostrar de qué modo se instauró la escuela francesa de biología molecular.
} 
de cómo se regula la síntesis de la enzima $B$-galactosidasa ${ }^{13}$ en la bacteria $E$. coli. Grosso modo, el fenómeno consiste en lo siguiente: en ausencia de lactosa, las bacterias no producen la enzima, pero cuando al medio se adiciona este azúcar, en unos cuantos minutos empieza la síntesis de dicha proteína. La comprensión de este fenómeno se basó en el hecho de que hay un represor, el cual es una proteína alostérica, que en estado activo se une al fragmento de ADN que codifica la información para la síntesis de la ß-galactosidasa (y otros genes estructurales asociados), impidiendo que el proceso de transcripción se lleve a cabo. Pero al estar presente la lactosa, ésta se une alostéricamente al represor haciéndole perder su configuración, desligándose así del ADN, lo cual permite que se dé inicio a la transcripción ${ }^{14}$.

Por su parte, el trabajo de Lwoff se enfocó en entender cómo se expresa la información genética en las bacterias lisogénicas. Dichas bacterias son las que han sido infectadas por bacteriófagos, pero no son lisadas inmediatamente, sino que el material genético viral se ensambla, por decirlo así, al genoma de la bacteria (lo cual se denomina profago), siendo transmitido a la siguiente generación. Cuando hay un cambio en el medio, como por ejemplo radiaciones ultra violeta, el genoma de los virus o se expresa y las bacterias se lisan, liberándose así una multitud de bacteriófagos. Estos dos trabajos, en apariencia tan diferentes, resultaron ser las dos caras de una moneda, cuando "Jacob se dio cuenta de que cada fenómeno, la inducción del profago de Lwoff y la estimulación de la producción de la enzima [ß-galactosidasa] por Monod, eran ambos el resultado de la expresión de un gene por la eliminación de un represor" (Ondarza, 1994, pp. 79-80).

Desde este punto de vista, podemos apreciar de qué manera estos tres biólogos franceses han constituido lo que Canguilhem (1975) denominó como una trinidad del saber, del saber biológico valga decir. En palabras de Canguilhem, una vez que los tres investigadores "recuperaron" sus respectivas identidades, cada uno de ellos se dedicó a escribir una obra sobre biología (enfatizando en lo molecular), con el objetivo de hacerla accesible al público en general. Sin ánimo de profundizar en ello, vale la pena que veamos algunos rasgos distintivos de cada una de esas contribuciones.

En primer lugar, André Lwoff ha propuesto algunas ideas sobre la organización de lo vivo en su obra "El orden biológico" (1998). En este libro, Lwoff presenta el contenido de los "descubrimientos" que los hicieron merecedores (a él y a sus colegas) del Premio Nobel. Para este autor, el organismo es un sistema complejo organizado capaz de reproducir su especie, el cual nunca aparece de novo, sino que siempre procede de un organismo preexistente. Asimismo, el organismo sintetiza las partes que lo constituyen, siempre y cuando se provea de alimento y energía. Desde el punto de vista de Lwoff, además de lo dicho anteriormente, hay dos rasgos fundamentales de lo vivo: la asimilación y el metabolismo.

Lwoff, es partidario de ir más allá de la estructura visible cuando dice: "a nosotros no nos interesa la apariencia externa de las cosas. No nos interesa lo que vemos, sino lo que no vemos, esto es, la esencia invisible de las cosas". De igual modo, hace mención al hecho de que "el mundo vivo está compuesto de millares de especies que difieren unas de otras en su tamaño, su forma, su composición química, su nutrición, su metabolismo, etc., pero todas estas especies están construidas con los mismos bloques estructurales" (Lwoff, 1998). Así, aunque haya una diferencia en cuanto a morfologías o estructuras visibles, existe en lo viviente una unidad a nivel molecular.

\footnotetext{
${ }^{13}$ Esta enzima hidroliza la lactosa, produciendo así, por cada molécula de ese disacárido, una molécula de glucosa y otra de galactosa.

${ }^{14}$ Este proceso lo explico detalladamente en Castro (2006).
} 
Para Lwoff, por otro lado, el orden biológico es la ordenación establecida en la constitución existente de los organismos; es una ordenación en el espacio y en el tiempo. El orden biológico es dual: estructural y funcional, estático y dinámico. El orden estructural hace referencia a lo estático y variable del $A D N^{15}$, mientras que el orden funcional es la dinámica del metabolismo: "El orden estructural y el orden funcional son aspectos complementarios del ser vivo" (ibíd.).

En suma, este biólogo "(...) ha demostrado cómo el orden funcional de la célula se ve confirmado por el conocimiento de sus alteraciones, el parasitismo viral; ha resumido finalmente lo esencial de las preguntas que los físicos y los biólogos plantean, en el terreno de la termodinámica y de la teoría de la información, referentes a las relaciones del orden y del desorden, de la organización y la entropía, para concluir que «la única fuente de orden biológico es el orden biológico»" (Canguilhem, 1975, p. 104).

Por su parte, Jacques Monod, en su libro "El azar y la necesidad" (1993), aborda el significado que tienen los hallazgos científicos en cuestión, anunciando el subtítulo de su obra como "un ensayo sobre la filosofía natural de la biología moderna". En esta obra, Monod "pretende sustentar en la biología macromolecular, gracias a las teorías de la herencia y de la evolución, la tarea de ofrecer una respuesta a las preguntas tradicionales y fundamentales de la teoría del conocimiento y de la práctica, es decir, de equipararse a una filosofía" (Canguilhem, 1975:105).

En este orden de ideas, en la obra de Monod encontramos una caracterización de los organismos como "extraños objetos", los cuales se distinguen por estar dotados de un proyecto teleonómico ${ }^{16}$ : "esto es la subordinación de la organización individual a un plan definido por la especie" (Maturana y Varela, 1994, p. 64). Por otro lado, para Monod los organismos son máquinas que se construyen a sí mismas, lo cual ha sido denominado por Maturana y Varela como autopoiesis. Al respecto, Monod afirma que los artefactos (y algunos objetos naturales como las rocas) surgen a partir de la acción de fuerzas externas, mientras que los organismos se autoconstruyen mediante fuerzas endógenas. A su vez, los organismos son máquinas que se reproducen y esta reproducción es invariante, es decir, que la cantidad de información transmitida de una generación a otra, en una especie dada, asegura la conservación de la norma estructural específica, lo cual no siempre es el caso, puesto que ocasionalmente se llevan a cabo "errores" o, más específicamente, mutaciones.

Asimismo, Monod hace una descripción de la teleonomía como dependiente del conjunto de proteínas estructurales y funcionales, mientras que la invariancia está ligada a los ácidos nucleicos. Para este autor hay ciertas doctrinas animistas y vitalistas que se caracterizan porque le dan primacía a la teleonomía sobre la invarinacia, mientras que para él ésta tiene la prioridad con respecto a aquélla: "o, para ser más explícito, la idea darwiniana de que la aparición, la evolución, el refinamiento progresivo de estructuras cada vez más intensamente teleonómicas, es debido a perturbaciones sobrevenidas a una estructura que poseía ya la propiedad de invariancia, capaz por consiguiente de "conservar el azar» y por ello de someter los efectos al juego de la selección natural" (Monod, 1993).

Por otra parte, según Monod, las proteínas, en especial las enzimas, son verdaderos demonios de Maxwell, ya que "gracias a su capacidad de formar, con otras moléculas,

\footnotetext{
${ }^{15}$ Sin duda esto puede parecer una paradoja, pero si se mira con detenimiento no lo es. El ADN es estático porque conserva la información de una manera casi invariable, pero, ocasionalmente, puede haber "errores" (como las mutaciones que implican la sustitución de un nucleótido por otro en el ADN, por ejemplo) que si son ventajosos para los organismos en cuestión, llegan a incorporarse en su genoma. Además hay una dualidad entre el ADN como estático y dinámico si se reconoce, como lo dejaron claro Lwoff, Jacob y Monod, que los genes no solamente son secuencias de nucleótidos (genes estructurales), sino que éstos también son reguladores: responden a los cambios del entorno.

${ }^{16}$ Término acuñado por Monod.
} 
complejos esteroespecíficos y no covalentes, las proteínas ejercen sus funciones “demoníacas»". Pero las proteínas también ejercen funciones reguladoras, gracias a sus propiedades alostéricas, como el represor del modelo del operón, y cumplen, a su vez, la función de construir al organismo, ya que espontáneamente algunos oligómeros se ensamblan con otros para formar unidades más complejas, como es el caso de las proteínas globulares. Podemos apreciar en estos planteamientos un nuevo mecanicismo (Castro, 2005), que hace referencia, entre otras cosas, a la autoconstrucción y a la autorregulación de las "máquinas vivientes".

Así las cosas, si el trabajo de Lwoff hace referencia al contenido de las investigaciones sobre el modelo del operón, y el de Monod da cuenta del significado filosófico de las mismas, "La lógica de lo viviente" de Jacob da cuenta de la historia ${ }^{17}$ que las ha hecho posibles (Canguilhem, 1975, p. 103). Podemos ver que la historia de la herencia que nos presenta Jacob es un ahondar en las estructuras de lo viviente: desde la estructura visible, pasando por la organización (que culmina en las células), adentrándonos luego a los cromosomas y los genes, hasta finalizar en las macromoléculas del ADN y ARN. La estrategia de Jacob en su libro se evidencia en la forma en que éste está estructurado:

En el primer capítulo se ocupa de cómo en los siglos anteriores al XIX, para dar cuenta de lo vivo, se aludía exclusivamente a las estructuras visibles. El tema del segundo capítulo es "la organización", que emergió en el siglo XIX, en donde ya no importa tanto lo visible de las estructuras, sino las relaciones invisibles entre ellas. El tercer capítulo se centra en el problema del tiempo en la explicación de lo vivo, o sea, la teoría de la evolución. En el cuarto capítulo se enfoca en la experimentación en biología, pero hace un especial énfasis en el trabajo de Mendel y los mendelianos. El quinto capítulo es el más relevante para el tema que nos ocupa, pues se centra en la biología molecular y, por supuesto, hace hincapié en los procesos de regulación génica. Finalmente, en las conclusiones, aborda su propuesta del "integron": las integraciones sucesivas de los sistemas vivientes.

Cabe resaltar que para Jacob "la reproducción de un organismo, se ha transformado en la de las moléculas que lo constituyen (...) el organismo se convierte así en la realización de un programa prescrito por la herencia ${ }^{18}$ [con el cual] desaparecen ciertas contradicciones que la biología había resumido en una serie de oposiciones: finalidad y mecanismo, necesidad y contingencia, estabilidad y variación" (Jacob, 1986).

Retomemos la idea de "integrón", con la cual Jacob plantea su visión acerca de cómo se conforma la complejidad del mundo viviente: "la complejidad de un organismo es tal que incluso el más simple de ellos seguramente no hubiera podido nunca formarse, reproducirse y evolucionar si el conjunto hubiese tenido que organizarse pieza por pieza, molécula por molécula como un mosaico (...) en vez de esto, los organismos se edifican por una serie de integraciones" (Jacob, 1986). Es a cada una de estas unidades o sistemas, que Jacob le da el nombre de integrón y para ejemplificar los sucesivos niveles de integración de dichas unidades él usa como analogía a las muñecas rusas, aunque sin duda en el mundo viviente el asunto es más complejo.

Desde luego que no ha sido mi interés hacer una reseña exhaustiva de cada una de las obras que he mencionado, sino que pretendo situarlas como una consecuencia ineludible de la publicación del modelo del operón, y de la obtención del Premio Nobel por parte de los biólogos aludidos. Desde mi punto de vista, estas obras aún son

\footnotetext{
${ }^{17}$ Es preciso anotar que esa historia es epistemológica, como la de Canguilhem.

${ }^{18}$ Se trata, desde luego, de un programa teleonómico, no teleológico, es decir, no intencional.
} 
fundamentales para todo aquél que quiera comprender algunos aspectos teóricos, históricos, filosóficos, e incluso técnicos, de dicho modelo científico y de la biología en general. Dichas obras, como el modelo del operón en sí, tienen, a mi modo de ver, importantes implicaciones didácticas en la actualidad. Pasemos a explicar este punto, a manera de conclusión.

Dije párrafo atrás que la biología molecular ha propiciado una nueva forma de entender lo vivo, perspectiva que he denominado como un (nuevo)mecanicismo, que no es sinónimo del que imperaba en los siglos XVII y XVIII. Este neomecanicismo habla de "máquinas" que se construyen a sí mismas, por lo que ya no es necesaria una voluntad externa, ya no es pertinente un constructor exógeno: los "planos" y las "herramientas" para construir estas "máquinas autopoiéticas", residen en el centro de su organización. Es evidente que los conceptos que propone la nueva biología hacen referencia a la formulación de modelos, como el del operón, que explican un fenómeno mediante un mecanismo, lo que conlleva que ya no nos hable de hechos directamente observables.

Una reflexión didáctica fundamental surge de esta situación: si queremos enseñar un tema como la regulación genética, y como ésta no parte de la evidencia observable a simple vista, entonces hemos de basarnos principalmente en la construcción y comprensión de modelos. Hace mucho tiempo se ha concluido que la construcción del conocimiento científico no se basa en la pura observación, sino que cobra relevancia la fundamentación de un marco teórico y experiencial en el cual las observaciones cobran sentido. Como hemos planteado en otros momentos (Castro y Valbuena, 2007; Castro, 2008), la modelización es una de las diversas estrategias para la enseñanza de la biología, pero este proceso no es totalmente independiente de otros, como la experimentación. Podemos ver estas relaciones en la siguiente cita:

\begin{abstract}
A partir de una representación determinada del sistema, se elaboraba un experimento que ponía a prueba uno u otro aspecto de esta representación. En función de los resultados, se modificaba la representación para preparar otro experimento y así sucesivamente. De este modo funcionaba la investigación en biología. Al contrario de lo que yo había creído, el procedimiento científico no consistía sencillamente en observar, en acumular datos experimentales para elaborar una teoría a partir de ellos, sino que se iniciaba con la invención de un mundo posible o de un fragmento de mundo posible, para irlo confrontando, a través de la experimentación, con el mundo exterior. Y era ese diálogo sin fin entre la imaginación y la experimentación lo que hacía posible la formación de una representación [un modelo] cada vez más ajustada de lo que se llama "la realidad" (Jacob, 1989)
\end{abstract}

En ese sentido, el conocimiento científico, y el biológico en particular, no consiste solamente en observar desprevenidamente el mundo. Reflexionemos sobre lo siguiente: mediante el uso del microscopio, algunos maestros creen que de esta manera sus estudiantes van a observar células, ¿pero ellos realmente observan células? Muy probablemente los estudiantes esperarán ver las células como se las muestran los libros de texto, lo cual nunca (o casi nunca) va a ocurrir. Por otro lado, al ser cortado y teñido el tejido, las células perderán muchas de sus cualidades, es decir, ya no son tales. Asimismo, si el estudiante no tiene una comprensión básica del concepto célula, no verá más que una serie de formas y colores sin sentido aparente: jarte abstracto!

Si la célula es un ente todavía observable, ¿qué ocurre entonces con lo que a nivel de la escuela y de muchas universidades es aún inobservable ${ }^{19}$ como las macromoléculas orgánicas, los procesos metabólicos, o los mecanismos de regulación

\footnotetext{
${ }^{19}$ Sin duda, en el contexto científico estas entidades y procesos no son observables en el sentido en el que lo son las células, por ejemplo, pero sí se pueden evidenciar algunas transformaciones o signos que permiten poner de presente, por poner un caso, que ha ocurrido el metabolismo de determinada sustancia en un cultivo de bacterias. A este respecto véase Moss (1997).
} 
genética?: la biología molecular ha construido una nueva concepción de lo vivo, que se basa en lo invisible, por lo tanto su enseñanza se debe basar en la construcción y comprensión de modelos mecanicistas.

Pero no debemos perder de vista que, según Jacob y otros autores, la "organización" fue una novedad conceptual que permitió el surgimiento de la biología en el siglo XIX. Dicho concepto ha sido esencial porque con él se pasó de una perspectiva que se basaba en las estructuras visibles, a una que hace hincapié en las relaciones no visibles que se establecen entre las diferentes estructuras de un organismo. Por ende, el neomecanicismo de la biología molecular no haría más que seguir allegando elementos para complejizar eso que entendemos por organización viviente, la cual no es algo transparente que se halle en el mundo a la espera de ser vislumbrada, sino representada.

En ese sentido, cabe recordar lo afirmado por Jacob en la extensa cita previa, y es que esas representaciones posibles del mundo deben ser puestas a prueba. Así, los modelos son construcciones que no nos dicen exactamente cómo es y cómo se comporta el sistema que estamos estudiando, pero sí nos dan indicios de que, dados los conocimientos teórico-prácticos de la ciencia en un determinado momento, esas son las mejores representaciones de las que disponemos. Y una vez que éstas demuestran su pertinencia, entonces no es extraño que devengan en objetos de enseñanza, en diferentes niveles de la educación formal.

Hay que agregar, sin embargo, que estos modelos no son, de ninguna manera, una simplificación del mundo, sino que con ellos podemos acceder a otros niveles de complejidad. Piénsese, por ejemplo, en las estrategias que han usado los científicos para elaborar el modelo del operón: alguien diría que son procesos reduccionistas, puesto que se trata de explicar lo macro, con respecto a lo micro (es decir a lo molecular), pero si nos detenemos a analizar con cuidado el sistema que este modelo representa, no será difícil concluir que es altamente complejo (Castro, 2010). Así pues, vale la pena preguntarnos: ¿qué tiene de especial el modelo del operón? En síntesis, dos cosas: 1) nos permite entender que los genes no son sólo estructurales, sino también reguladores, es decir, dinámicos y, en relación con ello, 2) nos permite ver las diversas maneras en que se relacionan los medios interno (sistema Lac de E. coli) y externo (por ejemplo un cultivo rico o pobre en lactosa) y, lo más importante: cómo se autorregula este medio interno, en especial en lo que atañe a la regulación genética, que implica, a su vez, una regulación metabólica.

Llegados a este punto debo decir que hay unas preguntas que han estado rondando toda mi discusión y que en estos momentos se tornan inaplazables: ¿es el modelo del operón Lac un objeto de la enseñanza de la biología? En caso afirmativo, ¿en qué medida lo es, o cuáles serían sus alcances? En caso negativo, ¿cuáles serían las razones de ello? Desde mi punto de vista, nos hallamos ante las dos situaciones. Este modelo sí es un objeto de enseñanza a nivel superior, y prueba de ello es que es abordado en textos universitarios de diferentes áreas como biología general, microbiología, bioquímica, biología celular y molecular, y genética, entre otras (Castro, 2006). Esto nos lleva a pensar que es un tema relevante para la formación de biólogos, profesores de biología y futuros profesionales de áreas afines.

Desde este punto de vista, cabe suponer que comprender la regulación génica es un tema ineludible para la formación de dichos profesionales, en el sentido de que les permite comprender, desde una perspectiva netamente molecular, un proceso que es central para la biología: la homeostasis, es decir, el equilibrio dinámico que caracteriza las interacciones entre el organismo y su entorno, como lo sostuve líneas atrás. Pero quizá lo más relevante es que este modelo ayuda a complejizar la idea misma de 
organización, la cual, como vimos, es medular para entender la biología en su conjunto.

En cuanto a la respuesta negativa, ésta nos remite a la educación básica y media (al menos en el contexto colombiano). Este tema está ausente, hasta donde yo sé, de los libros de texto para estos niveles, lo cual es un indicativo de que podría no hacer parte de los planes de estudio que dichos materiales didácticos ayudarían a desarrollar. Alguien podría explicar esta situación afirmando que el modelo del operón es muy complejo para estudiantes de los niveles aludidos, frente a lo cual podríamos contraargumentar diciendo que lo mismo se debería sostener con respecto al modelo de la doble hélice del ADN, propuesto por Watson y Crick en 1953 (claro, en igual condición se hallarían otros temas y/o modelos biológicos), pero este modelo sí hace parte de esos textos y de esos planes de estudio, y nadie dudará en decir que no se trata de un modelo fácil de comprender. ¿A qué responde esta situación?

Voy a aventurar una hipótesis: varios aspectos de nuestra cultura, dentro de ellos la enseñanza de la biología, están más permeados por lo que se propone en los países anglosajones que por los saberes provenientes de otras latitudes. Un ejemplo de ello, tomado de la filosofía e historia de las ciencias, es que conocemos mucho de las obras de Kuhn, Feyerabend y Popper, entre otros, pero son casi desconocidos por nosotros autores como Bachelard, Canguilhem y Foucault (aunque en realidad este último no es tan ignorado en nuestro contexto). ¡Y qué decir de los conocimientos que se producen en otras regiones del mundo, incluido nuestro propio país!

Ciertamente, mi hipótesis carece de sustento, pero por lo pronto no se me ocurre una explicación consistente de por qué el tema del modelo del operón Lac está ausente, hasta donde recuerdo, de los libros y planes de estudio aludidos. No creo que la respuesta, como ya anoté, radique en decir que ese modelo es muy complejo para que los estudiantes de esos niveles lo aprendan. Quizá esta situación sea un tema interesante de ser indagado, por lo que habrá que esperar qué nos enseñarían los resultados de esas investigaciones futuras. Mientras tanto, la pregunta queda abierta.

Por otra parte, no está de más recordar que en 2003 hubo bombos y platillos en todo el planeta para celebrar los 50 años del modelo de la doble hélice, y en especial la comunidad de biólogos realizó magnos eventos con ese motivo. Esto no tiene nada de malo, todo lo contrario. Lo que llama la atención es que haya habido sólo unos cuantos susurros para celebrar el mismo aniversario del modelo del operón Lac. No obstante vale la pena reconocer que las cosas importantes se pueden decir a viva voz o como un mero murmullo.

Jacob tenía razón cuando dijo, en la frase que usé como epígrafe, que a pesar del fracaso inicial, el modelo del operón ha demostrado ser verídico en esa región del universo que llamamos el sistema lactosa del colibacilo. Pero también es preciso decir que Monod no estaba del todo errado cuando sugirió que ese modelo era igualmente válido para el elefante, puesto que en el artículo de 1961, él y su colega, propusieron que entre el ADN y las proteínas debería haber un intermediario, que ellos denominaron mensajero estructural y asumieron que tenía que ser un polinucleótido. Como ya se habrá advertido, ellos postularon la existencia del ARN mensajero, nominación de su autoría, pero que no pudieron demostrar experimentalmente.

Como si fuera poco, Jacob y Monod hicieron patente que no hay ribosomas que se correspondan con la síntesis de tipos específicos de proteínas (como se creía en ese 
entonce ${ }^{20}$ ), sino que son, por decirlo así, universales, o sea que ellos son los sitios en que se lleva a cabo la construcción de las proteínas, en general. Así entonces, es importante resaltar que el ARN mensajero y los ribosomas son elementos imprescindibles en el proceso de traducción (síntesis de proteínas) para cualquier organismo, ya sea bacteria o elefante, por lo que no es descabellado decir que Monod tenía razón, al menos en el sentido señalado. En consecuencia, es gracias al modelo del operón $L a c$ que hemos empezado a comprender la regulación genética en diferentes tipos de organismos.

Para cerrar, debo reconocer que de no ser por la conferencia de Morange, esta conmemoración también habría pasado inadvertida para mí. Espero que este murmullo, es decir, este pequeño escrito, haga eco en quienes vean la necesidad de interrogarse acerca de la enseñabilidad de este interesante modelo, el cual nos ha abierto muchas puertas, y sin duda lo continuará haciendo.

\section{BIBLIOGRAFÍA}

Canguilhem, G. (1975). Lógica de lo viviente e historia de la biología. En Jacob, F., Senent-Josa, J., Jakobson, R., Levi-Strauss, C., Foucault, M., \& Canguilhem, G. Lógica de lo viviente e historia de la biología. Barcelona: Anagrama.

Castro, J.A. (2005). La biología molecular: una nueva concepción de lo vivo. En Tecné, Episteme y Didaxis. Bogotá: Universidad Pedagógica Nacional. Numero Extra, pp. 229-230.

Castro, J.A. (2006). Interrelaciones entre historia, epistemología y didáctica de las ciencias: el caso del modelo del operón lac en biología molecular. Un análisis de textos universitarios. Tesis de grado, Maestría en Docencia de la Química, Universidad Pedagógica Nacional, Bogotá. Mención de Honor en el IX Premio Nacional de Educación Francisca Radke, 2008.

Castro, J.A. (2007). El modelo de la historia social de las ciencias: un ejemplo a propósito del nacimiento de la biología molecular en Francia. En Tecné, Episteme y Didaxis. Universidad Pedagógica Nacional, Numero Extra, Septiembre de 2007, Medio Magnético (CD).

Castro, J.A. (2008). La modelización en la construcción del conocimiento científico: algunas confluencias entre ciencia y arte. En: Bio-Grafía. Escritos sobre la biología y su enseñanza, (1), Universidad Pedagógica Nacional. Disponible en: http://www.pedagogica.edu.co/revistas/ojs/index.php/bio-grafia/index

Castro, J.A. (2010). El gen: ¿Entidad dada o construida? Reflexiones sobre la historicidad de los objetos científicos. En: Bio-Grafía. Escritos sobre la biología y su enseñanza, vol, 3 (5), Disponible en http://www.pedagogica.edu.co/revistas/ojs/ index.php/bio-grafia/index

Castro J.A., \& Valbuena, E. (2007) ¿Qué biología enseñar y cómo hacerlo? Hacia una resignificación de la biología escolar. En Tecné, Episteme y Didaxis, (22), pp. 126-145.

\footnotetext{
${ }^{20}$ La idea de fondo, por ponerlo de algún modo, es que la proteína $A$ sería sintetizada en el ribosoma $A$, la enzima $X$ sería sintetizada en el ribosoma $X$, y así sucesivamente.
} 
García, V. (2009). Interruptores, baterías y redes. El manejo de la complejidad en la regulación genética. Tesis de Doctorado en Filosofía de la Ciencia, México: Universidad Nacional Autónoma de México.

Gayon, J., \& Burian, R. (2004). National traditions and the emergence of genetics: the French example. In Nature Reviews/Genetics, Vol. 5, February, pp. 150-156. Disponible en: http://www.nature.com/reviews/genetics

Jacob, F. La lógica de lo viviente. (1986). [1970]. Barcelona: Salvat Editores.

Jacob, F. (1989). La estatua interior. Barcelona: Tusquets.

Jacob, F., \& Monod, J. (1961). Genetic regulatory mechanisms in the synthesis of proteins. In Journal of Molecular Biology, (3), pp. 318-356.

Lwoff, A. (1998). [1966]. El orden biológico. México: Siglo XXI Editores.

Maturana, H., \& Varela, F. (1994). De máquinas y seres vivos. Autopoiesis: la organización de lo vivo. Santiago de Chile: Editorial Universitaria.

Monod, J. (1993). [1970]. El azar y la necesidad. Barcelona: Tusquets Editores.

Moss, R. (1997). A discovery lab for studying gene regulation. In The American Biology Teacher, Vol. 59, № 8, October, pp. 522-526.

Navarro, F. (2002). ¿Quién lo usó por vez primera? Operón. En Panace@, Vol. 3, № 7, Marzo, p. 5.

Ondarza, R. (1994). Biología molecular. Antes y después de la doble hélice. México: Siglo XXI Editores.

Thuillier, P. (1985). Cómo nació la biología molecular. En: Jacob, F., Monod, J., Calvin, M., Tatum, E., Brachet, J., Prigogine, I., Blangy, D., Bussard, A., Changeux, J-P., Thuillier, P., \& Volfin, P. Biología molecular (selecciones de la recherche). Barcelona: Orbis. 